\title{
The relationship between anxiety and shoulder injuries among South African university and club rugby players
}

\author{
R L van Niekerk, E Lynch \\ Department of Psychology, University of Johannesburg \\ R L van Niekerk, D Lit et Phil (Psychology) \\ Department of Sports Sciences, University of Johannesburg \\ E Lynch, BSc Hons (Sport Science)
}

Corresponding author: L van Niekerk (leonvn@uj.ac.za)

\begin{abstract}
Objectives. This correlational study investigated the relationship between competitive anxiety and shoulder injuries in a sample of club rugby players $(N=112)$ from two universities and three suburban clubs.

Methods. The participants were asked to complete a biographical questionnaire and the Sport Competition Anxiety Test, ${ }^{1}$ while the injury history of the players for the 2012 season was obtained from the responsible health professions after consent was given. Group differences and a direct logistical regression were calculated to determine the relationship between injury and anxiety.

Results. The results indicated that rugby players who contracted a shoulder injury in a 1-year season have significantly higher levels of anxiety than those players who did not. However, the effect size of the difference seems to be small. The anxiety levels of players with shoulder injuries were regarded as too high when competing. A logistical regression, including various factors, was able to predict injury fairly well, but anxiety seems to be the only variable that contributed significantly to the model.

Conclusion. The results suggest that the contribution of anxiety to the occurrence of shoulder injuries in club and university rugby cannot be ignored. The high level of anxiety associated with players who suffered shoulder injuries has to be targeted with anxiety management skills as part of a player development and injury management programme.
\end{abstract}

S Afr J SM 2012;24(4):107-111. DOI:10.7196/SAJSM.353

Various studies have attempted to explore the risk factors associated with injury in rugby. ${ }^{2}$ However, most of them focus their attention on biographical, physical, environmental and technical factors. The role of psychological factors such as anxiety is largely neglected, except for studies exploring the role of worry and stress in rugby injury. ${ }^{3}$ The rising occurrence rate of injuries in both professional and club rugby has posed a major challenge which has to be dealt with, ${ }^{4}$ more specifically at the South African university and club levels. ${ }^{5}$ Many coaches and talent scouts place much focus on the above abilities and promote programmes to develop bigger, physically stronger, faster and more talented players who can excel in their sport. ${ }^{6}$ Nonetheless, these programmes utilised for rugby players at university and club level did not provide adequate emphasis on the prevention and treatment management of previous injuries. ${ }^{6}$ As a result, injuries at university and club level may continue to increase unless preventive methods that are suited for the game of rugby are implemented. ${ }^{7}$

Because it is a contact sport, rugby poses a high risk for injury. ${ }^{8}$ Lower limbs are most often involved in rugby injuries, with the knee being the most frequent site. Shoulder injuries account for the second most loss in time (days) for rugby players. ${ }^{5}$ During the 2007 Rugby World Cup shoulder injuries accounted for the loss of 9.4/1 000 playing-hours. ${ }^{9}$

\section{Shoulder injuries in rugby}

Shoulder injuries account for $6-19 \%$ of joint injuries in rugby. Most of these injuries seem to be dislocations, amounting to $80 \%$ of all shoulder injuries among elite Australian rugby players ${ }^{10}$ and accounting for 123 days' absence for every 1000 playing hours among elite English rugby players. ${ }^{11}$ Acromioclavicular joint injury and shoulder impingement accounted for 55/1 000 and 54/1 000 days missed, respectively. ${ }^{11}$

A study by Headey et al. ${ }^{12}$ revealed alarming statistics on shoulder injuries in rugby. Damage to the acromioclavicular joint (32\%) and rotator cuff injury or shoulder impingement (23\%) made up the largest number of shoulder injuries. Yet, dislocation or shoulder instability, which made up $14 \%$ of shoulder injuries among rugby players, caused $42 \%$ of days missed per season due to injury. Therefore, dislocations seem to be the most costly shoulder injury to rugby players. Front-row forwards and backline players (centres and fullbacks) had the highest number of shoulder injuries.

Most of the research, however, focuses on understanding the physical reasons for shoulder injuries in rugby, and neglects psychological reasons such as anxiety as a contributing factor to shoulder injuries. This article explores the relationship between shoulder injuries and anxiety.

\section{Anxiety and shoulder injuries in rugby}

Anxiety has been defined as a negative mood state associated with worry and apprehension. ${ }^{13}$ Theoretically, anxiety in sport is conceptualised from an emotional perspective with both trait- and state-like characteristics. ${ }^{13}$ Anxiety has been conceptualised as a multidimensional construct and differentiated as somatic (muscle tension) or cognitive anxiety (worry). ${ }^{14}$ The relationship between anxiety and sport performance has been studied extensively, mostly showing a curvilinear relationship between anxiety and performance. Dunn and Sytoruik ${ }^{15}$ studied the causes of excessive worry in highcontact sport and found that four domains of sport were associated 
with anxiety. These include fear of failure, fear of negative social evaluation, fear of injury and fear of the unknown.

Psychological factors such as stress were found to be a good predictor of injury among New Zealand rugby players. Two studies investigating stressors among professional rugby union players found that injury was among the top three stressors reported by rugby players.Methods The specific objectives of this study were to explore the relationship between anxiety and shoulder injuries among university and club rugby players. Forthcoming from this aim, the following research questions were asked:

- What is the extent of shoulder injuries among university and club rugby players?

- What is the level of anxiety among university and club rugby players?

- Is there a relationship between anxiety and shoulder injuries among university and club rugby players?

The study therefore aimed to explore the constructs of shoulder injury and anxiety and examine the relationship between these constructs. Two universities and three inner-city rugby clubs were invited to participate in the study. Permission to do the study was granted by the management of all the clubs, except for one university that was not willing to disclose their injury records to the researchers. This was acceptable due to the competitive nature of university rugby. Players who gave their consent were asked to complete the questionnaires and their injury records were examined with the permission of the relevant health professionals.

\section{Sample}

A sample of 112 first-team rugby players with a mean age of $25.0 \pm 3.3$ (range: 20 - 35 years) from two universities ( $n=45,40 \%)$ and three urban clubs $(n=67,60 \%)$ were included in the study. The two universities included $28(25 \%)$ and $17(15 \%)$ and the clubs 27 (24\%), 18 (16\%) and 22 (20\%) of the participants respectively in the sample. Players were represented in all 15 positions with a distribution of $54(48 \%)$ backline and 58 (52\%) forward players in the sample. Instruments

\section{Biographical questionnaire}

Players were asked to complete a biographical section in the questionnaire. Various factors such as age and player position were assessed.

\section{Sport Competition Anxiety Test (SCAT)}

Players were asked to complete the SCAT, ${ }^{1}$ which consists of 15 questions on a 3-point Likert scale ( $1=$ 'hardly ever', $2=$ 'sometimes' and $3=$ 'often'). Only 10 of the questions are included in the calculation of the players' anxiety score. The test measures the players' anxiety levels in competition contexts. ${ }^{14}$ Norm scores were established by Martens ${ }^{1}$ and found to be comparable to athletes in the South African context ${ }^{20}$ as follows: a score of $10-16$ is regarded as low anxiety, $17-22$ as moderate anxiety and a score above 23 as high anxiety.

Athletes with moderate anxiety usually perform at best. The curvilinear relationship between anxiety and performance, however, implies that players with low or high anxiety will experience a decreased performance. ${ }^{1}$ Various researchers found high reliability and validity on the instrument with an internal consistency (Cronbach's alpha) of between 0.8 and 0.85 in their research ${ }^{1} \mathrm{~A}$ high internal consistency $(\alpha=0.934)$ was found for the SCAT in this research.

\section{Injury reports}

Player injuries were evaluated from a 1-year period injury report previously compiled by the respective club physiotherapist or biokineticist. A number of factors were considered, such as injury history, strength and conditioning history, pre-habilitation adherence (pre-injury treatment programme), mechanism of injury and expected return date. Results

The prevalence of shoulder injuries in the sample is presented in Table 1. Almost one-third ( $n=26,27 \%)$ of the players had a shoulder injuring during the year. A large group $(n=69,73 \%)$ did not have a shoulder injury. However, they might have had another type of injury not reported within the scope of this study. The anxiety levels of most players were moderate $(n=52,53 \%)$. Only $19 \%$ of the players had low anxiety. A significant group $(n=28,28 \%)$ of the sample reported high levels of anxiety when competing.

Further analysis (Table 2) applying an independent sample $t$-test indicated a statistically significant difference $(t(80)=0-3.01, p=0.003$, two-tailed) between the anxiety levels of players who had a shoulder injury $(M=23.54 \pm 5.98)$ and those who did not $(M=19.20 \pm 4.51)$. Players with shoulder injuries had significantly higher levels of anxiety, which placed them in a category with too high anxiety when competing. The players with no shoulder injuries reported moderate levels of anxiety. The mean difference $(4.34,95 \% \mathrm{CI}-7.20$ to -1.47$)$ indicated a small effect size (eta squared $=0.102$ ).

Most of the primary shoulder injuries were dislocations (31\%), followed by impingement (12\%) and rotator cuff strain (12\%). Other shoulder injuries (Table 3) were fewer in comparison. Most secondary shoulder injuries, however, were rotator cuff tears $(27 \%)$, followed by muscle tightness $(12 \%)$. The results further indicated that in a large proportion of players ( $81 \%)$ a first shoulder injury is followed by a second shoulder injury. The chances of a third shoulder injury, however, are slim, and $89 \%$ of the players did not suffer a tertiary injury.

Table 1. Prevalence of shoulder injuries and anxiety among Rugby Union players

\begin{tabular}{|c|c|c|c|}
\hline & Condition & $\begin{array}{l}\text { Frequency } \\
(n)\end{array}$ & $\begin{array}{l}\text { Proportion } \\
(\%)\end{array}$ \\
\hline \multirow[t]{2}{*}{ Presence of an injury } & No injury & 69 & 73 \\
\hline & Shoulder injury & 26 & 27 \\
\hline \multirow[t]{3}{*}{ Anxiety level } & Low & 19 & 19 \\
\hline & Moderate & 52 & 53 \\
\hline & High & 28 & 28 \\
\hline
\end{tabular}


The context in which the shoulder injuries were contracted was also investigated and is presented in Table 4. Most of the players who had a shoulder injury ( $n=20,77 \%)$ were part of a strength and conditioning programme and indicated that they adhered to it. However, fewer of these players $(n=14,54 \%)$ adhered to a pre-habilitation programme. Only 8 (31\%) players reported that their shoulder injuries were recurring injuries. The two factors implicated most frequently as the mechanism for injury were tackles $(n=16,62 \%)$ and overtraining/ incorrect training techniques $(n=8,31 \%)$. Most of the players $(n=8$, $31 \%)$ returned to play immediately, followed by $15-28$ days lost before expected return to play for 6 (23\%) players. Playing positions that were most at risk to contract a shoulder injury were those of centres and full-backs $(n=10,39 \%)$ and the tight five $(n=6,23 \%)$. A statistically significant difference was found between the anxiety levels of players who adhered to a strength and conditioning programme $(\mathrm{M}=19.16 \pm 3.95)$ and those who did not $(\mathrm{M}=21.67 \pm 6.35 ; t(97)=2.31$, $p=0.023$ two-tailed). This implies that players who adhere to such programmes are less anxious when competing. This was not the same for the adherence to a pre-habilitation programme. The anxiety levels for players who adhered to such a programme $(M=18.70 \pm 3.51)$ and players who did not $(M=20.30 \pm 5.18 ; t(97)=1.604, p=0.112$ two-tailed) were not statistically significant. Although players in the centre and full-back positions were more frequently at risk for an injury, there was no significant difference between the anxiety levels of player positions: backline $(\mathrm{M}=20.10 \pm 4.38)$ and forward players $(\mathrm{M}=19.45 \pm 5.07 ; t(97)=0.648, p=0.495$ two-tailed). No statistically significant differences were found for the other contextual factors associated with shoulder injuries among the participants.

A direct logistical regression was performed to determine the influence of various independent variables (age, anxiety, adherence to a strength and conditioning programme, adherence to a prehabilitation programme and playing position) on the prediction of a shoulder injury. Although the proposed model was not supported by the Omnibus Tests of Model Coefficients ( $\chi^{2}$ test must be significant), $\chi^{2}$ $(5, n=82)=9.36, p=0.096$ ( $\chi 2$-test must be significant), it was supported by the Hosmer-Lemeshow Goodness of Fit Test, $\chi^{2}(8, n=82)=10.62$, $p=0.224$ ( $\chi^{2}$ test should not be significant). This implies that the model was able to differentiate between players who were injured and those who were not. The model was able to explain between 11\% (Cox and Snell R squared) and 19\% (Nagelkerke R squared) of the variance in injury, and could classify $85 \%$ of the cases correctly. Only anxiety made a statistically significant contribution to the model (see Table

Table 2. Group comparisons for the relationship between anxiety and the presence of injuries among Rugby Union players

\begin{tabular}{llllll}
\hline & & Frequency & & Standard error & $\begin{array}{l}\boldsymbol{p} \text {-value } \\
(\text { sign })\end{array}$ \\
& Group & $(\boldsymbol{n})$ & Mean \pm SD & $($ mean $)$ & 0.003 \\
\hline Presence of an injury & No injury & 69 & $19.20 \pm 4.51$ & 0.543 & 1.659 \\
& Shoulder injury & 13 & $23.54 \pm 5.98$ &
\end{tabular}

Table 3. Type of shoulder injuries as a function of primary, secondary and tertiary injuries among Rugby Union players

\begin{tabular}{|c|c|c|c|c|c|c|}
\hline \multirow[t]{2}{*}{ Type of injury } & \multicolumn{2}{|c|}{ Primary injury } & \multicolumn{2}{|c|}{ Secondary injury } & \multicolumn{2}{|c|}{ Tertiary injury } \\
\hline & $\begin{array}{l}\text { Frequency } \\
(n)\end{array}$ & $\begin{array}{l}\text { Proportion } \\
(\%)\end{array}$ & $\begin{array}{l}\text { Frequency } \\
(n)\end{array}$ & $\begin{array}{l}\text { Proportion } \\
(\%)\end{array}$ & $\begin{array}{l}\text { Frequency } \\
(n)\end{array}$ & $\begin{array}{l}\text { Proportion } \\
(\%)\end{array}$ \\
\hline Dislocation & 8 & 31 & 1 & 3.8 & 0 & 0 \\
\hline Impingement & 3 & 12 & 2 & 7.7 & 0 & 0 \\
\hline Rotator cuff strain & 3 & 12 & 1 & 3.8 & 0 & 0 \\
\hline Subluxation & 2 & 7.7 & 1 & 3.8 & 1 & 3.8 \\
\hline Inflammation & 2 & 7.7 & 1 & 3.8 & 0 & 0 \\
\hline Muscle tightness & 2 & 7.7 & 3 & 12 & 0 & 0 \\
\hline Glenoid labrum tear & 1 & 3.8 & 1 & 3.8 & 0 & 0 \\
\hline Tendon muscle rupture & 1 & 3.8 & 0 & 0 & 0 & 0 \\
\hline Hill-Sachs lesion & 1 & 3.8 & 1 & 3.8 & 0 & 0 \\
\hline Tendonitis & 1 & 3.8 & 2 & 7.7 & 0 & 0 \\
\hline Nerve injuries & 1 & 3.8 & 0 & 0 & 1 & 3.8 \\
\hline Bone bruising & 1 & 3.8 & 1 & 3.8 & 0 & 0 \\
\hline Rotator cuff tear & 0 & 0 & 7 & 27 & 1 & 3.8 \\
\hline Acromioclavicular joint sprain & 0 & 0 & 2 & 7.7 & 0 & 0 \\
\hline None & 0 & 0 & 5 & 20 & 23 & 89 \\
\hline Total & 26 & 100 & 26 & 100 & 26 & 100 \\
\hline
\end{tabular}


5). Although it was not the strongest predictor of injury in the model, an odds ratio of 1.196 was recorded for anxiety. The implication is that players who were anxious during competition were 1.2 times more likely to get a shoulder injury.

\section{Discussion}

The results capsulated the costly effect of shoulder injuries among university and club rugby players. Despite the effort and pressure to deal with injuries ${ }^{4,5}$ and the promotion of prevention and injury management programmes, ${ }^{6}$ almost a third of the rugby players had a shoulder injury during a 1-year season, which is higher than found in other studies. ${ }^{10}$ The extent of the injuries kept the players out of the game for between 1 and 2 months, reflecting the playing time lost due to injury, which was equally alarming as that among elite rugby players. ${ }^{11}$ Regarding the type of injury, dislocations, impingements and rotator cuff strains made up most of the shoulder injuries. Various other studies found these types of injuries among the highest shoulder injuries contracted by rugby players. ${ }^{10-12}$ More than two-thirds of the

Table 4. Contextual factors associated with shoulder injuries in Rugby Union players

\begin{tabular}{|c|c|c|c|}
\hline Factor & Condition & $\begin{array}{l}\text { Frequency } \\
(n)\end{array}$ & $\begin{array}{l}\text { Proportion } \\
(\%)\end{array}$ \\
\hline \multirow[t]{2}{*}{ Adherence to a strength and conditioning programme } & Yes & 20 & 77 \\
\hline & No & 6 & 23 \\
\hline \multirow[t]{2}{*}{ Adherence to a pre-habilitation programme } & Yes & 14 & 54 \\
\hline & No & 12 & 46 \\
\hline \multirow[t]{2}{*}{ Recurring injury } & Yes & 8 & 31 \\
\hline & No & 18 & 69 \\
\hline \multirow[t]{3}{*}{ Mechanism of injury } & Tackle & 16 & 62 \\
\hline & $\begin{array}{l}\text { Overtraining and } \\
\text { incorrect training technique }\end{array}$ & 8 & 31 \\
\hline & Weight training & 2 & 7.7 \\
\hline \multirow[t]{7}{*}{ Expected days to return } & 0 days, currently training & 8 & 31 \\
\hline & 1 - 7 days & 4 & 15 \\
\hline & 8 - 14 days & 1 & 3.8 \\
\hline & 15 - 28 days & 6 & 23 \\
\hline & 29 - 42 days & 2 & 7.7 \\
\hline & 43 - 56 days & 4 & 15 \\
\hline & 57 - 112 days & 1 & 3.8 \\
\hline \multirow[t]{6}{*}{ Playing positions } & Centres and full-back & 10 & 39 \\
\hline & Tight five & 6 & 23 \\
\hline & Utility forwards & 4 & 15 \\
\hline & Loose forwards & 3 & 12 \\
\hline & Utility backs & 2 & 7.7 \\
\hline & Halves and wings & 1 & 3.8 \\
\hline
\end{tabular}

Table 5. Logistic regression predicting likelihood of a shoulder injury

\begin{tabular}{|c|c|c|c|c|c|c|c|c|}
\hline & \multirow[b]{2}{*}{ B } & \multirow[b]{2}{*}{ SE } & \multirow[b]{2}{*}{ Wald } & \multirow[b]{2}{*}{ df } & \multirow[b]{2}{*}{ Sig } & \multirow[b]{2}{*}{$\operatorname{Exp}(B)$} & \multicolumn{2}{|c|}{ 95\% CI for $\operatorname{EXP}(B)$} \\
\hline & & & & & & & Lower & Upper \\
\hline Age & -0.003 & 0.079 & 0.001 & 1 & 0.971 & 0.997 & 0.854 & 1.165 \\
\hline Anxiety & 0.179 & 0.073 & 6.016 & 1 & 0.014 & 1.196 & 1.037 & 1.380 \\
\hline Strength and conditioning & 0.401 & 0.764 & 0.275 & 1 & 0.600 & 1.493 & 0.334 & 6.669 \\
\hline Pre-habilitation programme & -0.238 & 0.969 & 0.060 & 1 & 0.806 & 0.788 & 0.118 & 5.269 \\
\hline Playing position & 0.459 & 0.661 & 0.482 & 1 & 0.487 & 1.582 & 0.434 & 5.774 \\
\hline constant & -5.579 & 2.403 & 5.389 & 1 & 0.020 & 0.004 & & \\
\hline
\end{tabular}


shoulder injuries were due to the mechanisms of tackling. These results emphasise the high risk ${ }^{2}$ that the nature of the sport ${ }^{11,12}$ presents. In this regard, the player positions at a higher risk to contract a shoulder injury were the centers, full-backs and tight five.

Although most of the players adhered to a strength and conditioning programme, almost half did not adhere to a pre-habilitation programme. This might be due to the focus of scouts and coaches on developing bigger, physically stronger and faster players ${ }^{6}$ at the expense of preventing injuries. An alarming result in this regard was the high number of players who had a second shoulder injury: 4 in every 5 players who contracted a shoulder injury also contracted a second shoulder injury, while a third of the shoulder injuries were reported to be a recurring injury.

The role of anxiety in shoulder injuries cannot be ignored, as there was a significant difference between the anxiety levels of players with and without shoulder injuries. Those who contracted shoulder injuries had much higher anxiety than those who did not. Their anxiety put them in a category too high ${ }^{2,14}$ for effective performance. Further, anxiety was the only factor in a logistical regression that significantly contributed (11 - 19\% of the variance) to the prediction of a shoulder injury among university and club rugby players. As anxiety is associated with muscle tension and narrowing of attention, ${ }^{17}$ its role in the tightening of shoulders during tackling and unsuspected tackling (due to too narrow attention) should not be underestimated. These results suggest that the inclusion of anxiety management techniques during training and competition should be considered. Anxiety and apprehension, ${ }^{13}$ general fears and fear of re-injury, ${ }^{15}$ stress $^{18}$ and concern ${ }^{3,19}$ among rugby players are all related to injuries. ${ }^{16}$

\section{References}

1. Martens R. Sport Competition Anxiety Test. Champaign: Human Kinetics, 1982.

2. Chalmers DJ, Samanarayaka A, Gulliver P, McNoe B. Risk factors for injury in rugby union football in New Zeeland: a cohort study. Br J Sports Med 2012;46(2):95-102. [http://dx.doi.org/10.1136/bjsports-2011-090272]

3. Nicholls AR, Jones CR, Polman RCJ, Borkoles E. Acute sport-related stressors, coping and emotion among professional rugby union players during training and matches. Scand J Med Sci Sports 2009;19(1):113-120.

4. Garraway WM, Lee AJ, Hutton SJ, Russell EB, MacLeod DA. Impact of professionalism on injuries in rugby union. Br J Sports Med 2000;34(5):348-351. [http://dx.doi. org/10.1136/bjsm.34.5.348]

5. Gray J. Preventative rehabilitation for rugby injuries to the shoulder. Cape Town:SA Rugby, 2009. http://www.sarugby.co.za/boksmart/pdf (accessed 18 September 2012).

6. Quarrie KL, Handcock P, Toomey MJ, Walter AE. The New Zeeland rugby injury and performance project IV: Anthropometric and physical performance comparisons between positional categories of senior A rugby players. Br J Sports Med 1996;30(1): 53-55.

7. Erasmus H, Spamer EJ. Effect of a prevention programme on the incidence of rugby injuries among 15 and 16 year-old schoolboys. S Afr J Sports Med 2007;19(2):46-57.
8. Fuller C, Drawer S. The application of risk management in sports. J Sports Med 2004;34(6):349-356.

9. Fuller CW, Laborde F, Leather RJ, Molloy MG. International Rugby Board Rugby World Cup 2007 injury surveillance study. Br J Sports Med 2008;42:452-459.

10. Bathgate A, Best JP, Craig G, Jamieson M. A prospective study of injuries to elite Australian rugby union players. Br J Sports Med 2002;36:265-269. [http://dx.doi. org/10.1136/bjsm.36.4.265]

11. Brooks HJM, Fuller CW, Kemp SPT, Reddin DB. A prospective study of injuries and training amongst the England 2003 Rugby World Cup squad. Br J Sports Med 2005;39:288-293. [http://dx.doi.org/10.1136/bjsm.2004.013391]

12. Headey J, Brooks JHM, Kemp SPT. The epidemiology of shoulder injuries in English professional rugby union. Am J Sports Med 2007;35(9):1537-1543.

13. Weinberg RS, Gould D. Foundations of Sport and Exercise Psychology. Champaign: Human Kinetics, 2011.

14. Martens R, Vealy RS, Burton D. Competitive Anxiety in Sport. Champaigne: Human Kinetics, 1990.

15. Dunn JGH, Sytoruik DG. An investigation of multidimensional worry dispositions in a high contact sport. Psychology of Sport and Exercise 2003;4:265-282. [http://dx.doi. org/10.1016/S1469-0292(02)00005-5]

16. Cassidy CM. Understanding sport-injury anxiety. Athletic Therapy Today 2006;11(4):57-58.

17. Andersen MB, Williams JM. A model of stress and athletic injury: prediction and prevention. Journal of Sport and Exercise Psychology 1988;10(3):294-306.

18. Maddison R, Prapavessis H. The psychological approach to the prediction and prevention of athletic injury. Journal of Sport and Exercise Psychology 2005;27(3):289310

19. Nicholls AR, Backhouse SH, Polman RCJ, McKenna J. Stressors and affective states among professional rugby union players. Scand J Med Sci Sports 2009;19:121-128.

20. Potgieter J. Norms for the Sport Competition Anxiety Test (SCAT). South African Journal for Research in Sport, Physical Education, and Recreation 2009;31(1):69-79. 